\title{
NECESSIDADES INFORMACIONAIS DE IDOSOS EM BIBLIOTECAS COMUNITÁRIAS: estudo realizado em uma biblioteca no município de Fortaleza, Ceará
}

\author{
INFORMATION NEEDS OF ELDERLY IN LIBRARIES COMMUNITIES: a \\ study carried out in a library in the municipality of Fortaleza, Ceará
}

\author{
Ana Pricila Celedônio da Silva \\ UFC \\ Maria de Fátima Oliveira Costa \\ UFC \\ Lídia Eugenia Cavalcante
}

UFC

\section{RESUMO}

Apresenta estudo acerca das necessidades informacionais de idosos em contextos locais, tendo como objeto de estudo um grupo de idosos moradores do entorno da Biblioteca Comunitária Criança Feliz, localizada no Bairro Jardim Iracema, na cidade de Fortaleza, Ceará. Foram realizadas discussões teóricas acerca das temáticas: biblioteca comunitária, necessidades informacionais e, ainda, sobre idosos. No que tange à metodologia, a pesquisa possui abordagem qualitativa, exploratória e descritiva. Dentre os instrumentos de coleta de dados utilizados, valeu-se da entrevista semiestruturada e da pesquisa participativa, por meio da realização de roda de conversa e dinâmicas com os idosos. Para análise dos dados, utilizou-se a análise de conteúdo e o modelo Everyday Life Information Seeking (ELIS) concebido por Savolainen (1995). 0 estudo revelou que as necessidades informacionais do grupo estudado estão relacionadas principalmente às questões do cotidiano, como transportes e saúde. Constatou-se, ainda, a necessidade de que a biblioteca, lócus desta pesquisa, realize estudos de usuários com periodicidade que contemplem todos os públicos pertencentes à comunidade, inclusive os idosos, para assim atuar de forma inclusiva e democrática.

Palavras-chave: Biblioteca Comunitária. Necessidades de Informação. Necessidades Informacionais de Idosos. Biblioteca Comunitária Criança Feliz.

\section{ABSTRACT}

It presents a study about the informational needs of the elderly in local contexts, with the object of study being a group of elderly people living near the Biblioteca ComunitáriaCriança Feliz, located in Jardim Iracema neighborhood, in the city of Fortaleza, Ceará. Theoretical discussions about the themes were: community library, informational needs and, also, about the elderly. Regarding the methodology, the research has a qualitative, exploratory and descriptive approach. Among the data collection instruments used, we used the semi-structured interview and the participatory research, by means of a conversation wheel and dynamics with the elderly. To analyze the data, we used the content analysis and the Everyday Life Information Seeking (ELIS) model conceived by Savolainen (1995). The study revealed that the informational needs of the group studied are mainly related to everyday issues such as transportation and health. It was also verified the need for the library, locus of this research, to carry out studies of users with periodicity that contemplate all the public belonging to the community, including the elderly, in order to act in an inclusive and democratic way.

Keywords: Community Library. Information Needs. Information Needs of the elderly. Community library Criança Feliz. 


\section{INTRODUÇÃO}

As bibliotecas comunitárias têm tido papel singular no que se refere à democratização do acesso à leitura e à informação em contextos locais no Brasil. Esses espaços são oriundos de inciativas populares, localizadas em zonas periféricas ou rurais que, de modo geral, encontram-se distantes das bibliotecas públicas estaduais e municipais ou de outros equipamentos públicos e culturais mantidos pelo governo. Surgem, em muitos casos, justamente do desejo dessas comunidades de terem acesso à biblioteca, à leitura, ao livro e à informação.

Para que a biblioteca comunitária possa cumprir seu objetivo de democratizar o acesso à informação, no local onde está inserida, torna-se imperativo conhecer as necessidades informacionais dos indivíduos da comunidade, incluindo os diversos grupos que fazem parte da mesma, como por exemplo, os grupos da terceira idade.

$\mathrm{Na}$ literatura da área foram localizados muitos trabalhos voltados para estudos de usuários em que suas temáticas concentram-se nas necessidades informacionais de um determinado grupo. Entretanto, no âmbito dos estudos das bibliotecas comunitárias, pesquisas sobre necessidades informacionais são, ainda, escassas.

No presente estudo, a preocupação recai sobre as necessidades informacionais de idosos em contextos locais e sobre como as bibliotecas comunitárias têm se portado em relação a esse público. Nesse sentido, a pesquisa teve como objetivo: identificar as necessidades de informação de um grupo de idosos, moradores do entorno da Biblioteca Comunitária Criança Feliz (BCCF), localizada no bairro Jardim Iracema, na cidade de Fortaleza, Ceará.

As necessidades informacionais da população idosa encontram-se ligadas a diversas possibilidades, especialmente relacionadas ao cotidiano, vida profissional, lazer e saúde, dentre outras. Todavia, neste estudo, dá-se ênfase às demandas de informação dos idosos com relação ao seu contexto cotidiano e, para isso, se recorreu ao modelo Everyday Life Information Seeking (ELIS) concebido por Savolainen (1995).

\section{BIBLIOTECA COMUNITÁRIA: conceito e características}

A biblioteca comunitária possui características que a diferenciam de outros tipos de biblioteca. Essas singularidades são identificadas por Machado (2008) como: a forma 
de constituição, visto que são formadas e criadas pela comunidade a que pertencem; $o$ combate conjunto à exclusão informacional como forma de possibilitar a igualdade e justiça social; o processo de articulação dos indivíduos da comunidade; a localização dentro de uma comunidade; e o fato de não estarem ligadas diretamente a órgãos governamentais.

Machado (2008, p.64) sintetiza essas características ao definir a biblioteca comunitária como:

\begin{abstract}
Um projeto social que tem por objetivo estabelecer-se como uma entidade autônoma, sem vínculo direto com instituições governamentais, articuladas com as instâncias públicas e privadas locais, liderados por um grupo organizado de pessoas, com o objetivo comum de ampliar o acesso da comunidade à informação, a leitura e ao livro, com vistas a sua emancipação social.
\end{abstract}

Assim, podem-se observar como características intrínsecas e indissociáveis da biblioteca comunitária, a gestão autônoma e participativa e a democratização do acesso à leitura e à informação. Esses espaços, segundo Alves, Salcedo e Correa (2016, p.41), são “[...] uma expressão nítida desse processo que busca por meio da leitura e ação cultural fomentar a educação dos moradores da região como forma de incluí-los no espaço social e oferecer a oportunidade de estabelecimento de sua cidadania. "

É possível ver imbricada à concepção e aos objetivos que regem a biblioteca comunitária uma forte função social, e a busca pela inclusão informacional reafirma essa função. A biblioteca comunitária, quando torna-se efetiva nessa busca, pode contribuir junto à comunidade na qual está inserida, em diversos aspectos, como no auxílio à tomada de decisões relativas a solução de problemas do cotidiano; na colaboração informacional à implantação de pequenos negócios; no fortalecimento de associações, sindicatos e cooperativas; ajudando a resolver problemas jurídicos etc. de modo a contribuir com o desenvolvimento local e a qualidade de vida das pessoas (CAVALCANTE, 2014).

Os tipos de serviços oferecidos nesses espaços estão muitas vezes ligados a ações de fomento à leitura e atividades culturais. Machado (2008) identifica algumas atividades realizadas no âmbito dessas bibliotecas, sendo elas: a mediação de leitura, saraus literários, cursos de capacitação e aperfeiçoamento, palestras, seminários, 
concursos de poesia, oficinas de artesanatos, além de serviços como empréstimo de livros, acesso à internet e pesquisa local.

No que se refere aos usuários, Machado (2008) indica que, em geral, as bibliotecas comunitárias se mobilizam em esforço conjunto para atender às necessidades educacionais e culturais da comunidade, o que envolve, então, crianças, jovens, adultos e idosos. Entretanto, a autora chama a atenção que, em alguns casos, essas bibliotecas podem desenvolver atividades focadas em um grupo específico, como crianças ou idosos, devido a alguma particularidade da comunidade.

Para ir ao encontro das necessidades educacionais e culturais da comunidade, torna-se necessário conhecer o que a comunidade como um todo (independente do ciclo de vida em que seus indivíduos se encontram), necessita em termos de informação. Além disso, é preciso ter em perspectiva que os fluxos informacionais presentes nesses contextos podem possuir características bastante distintas, pois é importante ter em mente que "pensar as demandas informacionais das comunidades locais é aferir a elas novas formas de mediação. " (CAVALCANTE, 2014, p. 261).

Um ponto a se destacar sobre os usuários de bibliotecas comunitárias é que estes são "[...] tão híbridos em suas demandas quanto às informações que desejam receber e às muitas que podem produzir sobre seus contextos, memórias e identidades comunitárias." (CAVALCANTE, 2014, p. 262). Ou seja, diferente de outros tipos de bibliotecas, as necessidades e demandas desses usuários poderão ser bastante diversas, podendo ir desde questões educacionais, como respostas para uma tarefa escolar, como ao atendimento de demandas mais complexas e do cotidiano relacionadas a saúde, trabalho, lazer, etc.

O caráter autônomo proporcionado pela gestão participativa comunitária desses espaços informacionais, que é uma das principais características dessas bibliotecas, auxilia e a torna mais livre para seguir esse processo dialógico. Diferente de bibliotecas ligadas a órgãos governamentais, por exemplo, a biblioteca pública, as comunitárias possuem a liberdade de seguir um projeto político social criado de forma dinâmica e construído levando-se em consideração o seu contexto social e as necessidades de seus indivíduos.

Sob essas circunstâncias, entende-se que os estudos de usuários em contextos como o das bibliotecas comunitárias são imprescindíveis para que alcancem seu objetivo 
de inclusão, ressaltando que esses estudos contemplem também os grupos de terceira idade.

\section{AS NECESSIDADES INFORMACIONAIS E OS IDOSOS}

Definir o que seria necessidade parece ser uma tarefa bastante complexa, visto que o seu significado evoca diversos entendimentos. Porém, se acrescentarmos o termo informacional, adotamos assim uma especificação do tipo de necessidade a qual nos referimos, esclarecendo e delimitando a perspectiva que pretendemos estudar.

Cunha, Amaral e Dantas (2015) iniciam sua obra acerca dos estudos de usuários da informação, refletindo que a informação faz parte do cotidiano de todas as pessoas. Ela é necessária quando precisamos nos locomover, fazer compras, tomar uma decisão nos ambientes de trabalho, de negócio, etc., ou seja, necessitamos de informação a todo momento. Os autores, alertam, entretanto, que é certo que os indivíduos precisam de informação, “[...] mas, cada ser humano é um universo único e vive de modo diverso o seu ciclo de vida. Em cada idade, em cada profissão, em cada momento, as pessoas podem precisar de informações diferentes."

Para Figueiredo (1994) as necessidades informacionais podem ser compreendidas de duas maneiras, uma em função do conhecimento, que seria a necessidade que resulta do desejo de saber. E a necessidade de informação em função da ação, que pode ser entendida como a necessidade para a realização de atividades humanas, profissionais e pessoais.

Le Coadic (2004) apresenta algumas tipologias de necessidades de informação, as quais o autor divide em função: do conhecimento, que se origina no desejo de saber; $d a$ ação, que surge devido a necessidades de ordem materiais, profissionais, de necessidades básicas, como comer, dormir, dentre outras; de necessidade humana, quando a informação é necessária para satisfazer uma necessidade específica; dos desejos, aquilo que o indivíduo gostaria de ter, podendo ou não estar relacionada às suas necessidades; das demandas, aquilo que o indivíduo expressa e pede, o que indica que o uso daquilo que está a exigir; e do uso, aquilo que o indivíduos utiliza no tocante a informação.

A Pirâmide das Necessidades (Figura 1) desenvolvida por Barreto (2002), inspirada pela pirâmide das necessidades humanas e comportamentos desenvolvida por Inf. Pauta, Fortaleza, CE, v. 2, número especial, out. 2017 
Maslow, representa os níveis de necessidades informacionais dos indivíduos e o tipo de informação necessária em cada nível. Observa-se na figura abaixo, a existência de duas pirâmides, na primeira delas, encontra-se os três níveis de necessidades informacionais, onde cada nível representa um estágio das necessidades informacionais, e a passagem para cada nível ocorre apenas quando as demandas do estágio forem alcançadas. $\mathrm{Na}$ base da pirâmide, estariam as necessidades básicas, como alimentação, moradia, saúde e educação, e esse primeiro estágio, demanda informações do tipo utilitária. No segundo nível da pirâmide, encontram-se as necessidades dos indivíduos de participação e a permanência destes nos grupos que participam, como no trabalho ou na comunidade. Nesse nível, são necessárias informações ligadas ao âmbito profissional, por exemplo. No topo da pirâmide, depois de passar pelos dois primeiros níveis, seriam necessárias informações que conduza a reflexão, a realização pessoal e ao sucesso profissional, demandando nesse último estágio, informações do tipo seletivas. Barreto (2002, p. 5-6), comenta sobre os tipos de necessidades e os seus respectivos tipos de informação que,

A oferta de informação, ou seja, a estrutura dos estoques, relaciona-se à demanda como uma pirâmide invertida, inversamente proporcional, em termos quantitativos e qualitativos às posições da informação demandada, configurando situações de racionamento e excedente de informação nos seus extremos.

Figura 1 - As necessidades informacionais e os estoques de informação



Fonte: Barreto (2002, p. 6).

Outra perspectiva acerca das necessidades informacionais é proposta por Savolainen (1995), onde esse autor apresenta as necessidades e buscas informacionais a 
partir do contexto cotidiano, da vida diária. Em seu modelo Everyday Life Information Seeking (ELIS), o autor dá ênfase à busca pela informação que acontece no dia a dia, que é referente ao lazer, saúde, convívio social e locomoção, dentre outros aspectos. Se relacionarmos à Pirâmide de Barreto (2002), poderíamos dizer que o tipo de informação a qual Savolainen (1995) se refere seriam aquelas contidas na base, as necessidades básicas que requerem informações do tipo utilitária. Segundo Savolainen (1995), os estudos acerca deste tipo de necessidade informacional são muitas vezes ofuscados por estudos voltados a informação para a área científica, profissional e de negócios. 0 modelo de Savolainen (1995) pode ser visto na Figura 2.

No modelo de Savolainen (1995) são evidenciadas questões como ocupação do tempo e vida diária, situações problemáticas relacionadas ao dia a dia dos indivíduos, e o comportamento destes para solução desses problemas. O autor apresenta ainda, os fatores situacionais que podem vir a influenciar nesses momentos, como o capital financeiro, social, educacional e cultural dos indivíduos.

Figura 2 - Modelo Everyday Life Information Seeking (ELIS)



Fonte: Savolainen (1995). 
Diante dessas reflexões, como a população idosa se insere nesses estudos acerca das necessidades informacionais? Será que o ciclo de vida em que os mesmos se encontram influencia na forma como precisam de informação? Pires e Barreira (2015, p. 34) afirmam que em relação "à população idosa, as demandas de informação geralmente estão relacionadas à obtenção de novos saberes e da necessidade de usar a informação para realizar atividades do seu cotidiano." Os autores refletem ainda que,

Torna-se importante destacar que o grupo social dos idosos, se encontra diante de várias demandas informacionais no seu cotidiano, que nem sempre são supridas, apesar de serem reconhecidas e que precisam de informação para a solução de problemas de ordem pessoal, do conhecimento, de lazer, saúde e voltadas para a sua interação social. (2015, p. 34).

Nessa mesma perspectiva, Costa e Silva (2011) discutem a importância de se perceber que os grupos da terceira idade possuem demandas informacionais ligadas a diversos contextos, e que é imperativo possibilitar à população idosa o acesso à informação, para que possa estar apta a exercer sua cidadania de forma autônoma.

Com a aprovação do Estatuto do Idoso, em 2003, um novo olhar é dado com relação a este grupo, que passa a ser visto como sujeito de direitos. Entretanto, os preconceitos acerca do envelhecimento são ainda bastante presente em nossa sociedade. Segundo Whitaker (2007, p. 180),

\begin{abstract}
A sociedade precisa ser educada para compreender o envelhecimento sobre esse novo prisma. Está na hora de repensar as atitudes que infantilizam o idoso e o assistencialismo, que, principalmente nas camadas exploradas, trata-o como indigente, transformando em esmola, ou favor, as poucas políticas públicas que amenizam essa fase da existência, em relação às quais se configuram direitos humanos estabelecidos como direitos sociais.
\end{abstract}

Lucca e Vitorino (2015, p. 7) observam que, por muito tempo “[...] o período da velhice foi marcado pela decadência e incapacidade, porém atualmente percebemos que esta camada da população tem conquistado qualidade de vida. " Os autores afirmam ainda que a denominação "idoso" tem sido rejeitada por esse grupo, pois a mesma é muitas vezes carregada de significados que remetem a um sentido negativo. Segundo os autores, a expressão "terceira idade" surge como reflexo de um desejo desses sujeitos de serem vistos como indivíduos ativos, e que estão inseridos também em diversos círculos e atividades sociais. 
Os idosos, assim como os demais cidadãos brasileiros, devem estar contemplados nas políticas de acesso e inclusão educacional, informacional e digital. Porém, o planejamento dessas ações muitas vezes segue formatos e padrões que desconsideram fatores importantes como aspectos culturais, sociais e os interesses e necessidades informacionais desses indivíduos.

Portanto, ao pensar as necessidades informacionais de indivíduos que se encontram na chamada terceira idade, devemos levar em consideração que é necessário evitar os estereótipos que envolvem esses grupos, que assim como os demais usuários da informação, suas necessidades informacionais podem estar relacionadas, além do quesito idade, também aos contextos e dinâmicas sociais nos quais estes indivíduos estão envolvidos.

\section{PERCURSOS METODOLÓGICOS}

Os percursos metodológicos deste estudo tiveram como base a abordagem qualitativa, tendo em vista uma reflexão crítica acerca da temática que envolve os estudos das necessidades informacionais, como também pela intenção de uma análise aprofundada do objeto de estudo.

Combinamos a utilização de dois tipos de pesquisa, a exploratória e a descritiva, haja vista o imperativo de explorar conteúdos relacionados à temática aqui estudada e pelo estudo das características de um grupo. Segundo Gil (2008, p. 44), as pesquisas descritivas "juntamente com as pesquisas exploratórias, são as que habilmente realizam os pesquisadores sociais preocupados com a atuação prática. "

Para coletar os dados necessários à pesquisa utilizamos dois instrumentos de coleta de dados, o primeiro deles foi a entrevista do tipo semiestruturada, destinada à gestora da biblioteca. As questões norteadoras da entrevista foram relacionadas principalmente a aspectos como: o contexto histórico da unidade de informação, seus serviços e, a caracterização do público que frequenta a biblioteca.

O segundo instrumento foi a pesquisa participativa através de roda de conversa e dinâmicas. Este estudo de grupo aconteceu por meio de um encontro realizado na biblioteca pesquisada, que contou com a participação de sete (7) idosos, moradores do entorno da BCCF. Segundo Murani et al (2008, p. 114) “[...] a utilização desse tipo de técnica é bastante adequada à abordagem de grupos sociais atingidos coletivamente por Inf. Pauta, Fortaleza, CE, v. 2, número especial, out. 2017 
fatos ou situações específicas." De acordo com os autores, oficinas, dinâmicas, workshops, são exemplos de alguns tipos de estudos de grupos.

O planejamento, divulgação e aplicação dos instrumentos de coleta de dados ocorreram no intervalo de tempo correspondente a um mês, envolvendo os meses de outubro e novembro de 2016.

Tendo em vista os pressupostos da abordagem qualitativa, recorremos a técnica da análise de conteúdo, para analisar os dados coletados na entrevista e na atividade realizada na BCCF. Nessa metodologia de análise, deve-se ter por base uma definição precisa dos objetivos da pesquisa realizada. Umas das técnicas mais utilizadas na análise de conteúdo é a categorização, a qual se encontra entre as possibilidades "[...] mais rápida e eficaz, sempre que se aplique a conteúdos diretos (manifestos) e simples." (RICHARDSON,1985, p. 243).

Como forma de analisar e apresentar a interpretação dos dados, utilizamos como categorias as etapas do modelo Everyday Life Information Seeking (ELIS), concebido por Savolainen (1995). As categorias observadas no modelo foram: ocupação do tempo e vida diária, situações problemáticas, comportamento para solução dos problemas e os fatores situacionais.

\subsection{O LÓCUS DA PESQUISA: comunidade e biblioteca}

O lócus de realização do estudo foi a Biblioteca Comunitária Criança Feliz (BCCF), localizada no bairro Jardim Iracema, na cidade de Fortaleza-CE. De acordo com o Instituto de Pesquisa e Estratégia Econômica do Ceará (IPECE), o bairro onde está situada a biblioteca possui aproximadamente 23.184 habitantes, onde $7 \%$ destes são de pessoas acima dos sessenta e cinco anos de idade (IPECE, 2012).

A BCCF foi criada no ano de 1994, estando articulada ao Projeto Criança Feliz (PROCIF), do bairro Jardim Iracema e também à Rede de Bibliotecas do Polo de Leitura Jangada Literária, criada em 2012. O principal objetivo da BCCF é a democratização do acesso ao livro, à leitura e à informação. Nesse intuito, a biblioteca oferece serviços de empréstimos, mediações de leitura e, ainda, atividades externas à biblioteca, como: o projeto Quero mais Leitura, o Pé na Rua, o Projeto Comu-Lê e o Projeto Quintais com Letrinhas. 
Segundo informações fornecidas pela gestão da biblioteca, estão cadastrados cerca de 1070 usuários, com idade entre cinco e setenta anos. A maior parte do público que costuma frequentar e realizar empréstimo na biblioteca são as crianças e os adolescentes. Em relação ao público idoso, observa-se que a frequência ainda é considerada baixa.

\section{INTERPRETAÇÃO DOS DADOS COLETADOS}

De posse das informações colhidas junto a gestão da biblioteca e guiados pelo objetivo de conhecer as necessidades informacionais dos idosos do entorno da BCCF, organizamos e realizamos de forma conjunta a equipe gestora da instituição, a atividade intitulada "Café com Leitura e Afeto". A atividade contou com momentos de mediação de leitura, roda de conversa e dinâmicas.

Durante a roda de conversa, buscamos, dentre outros aspectos, identificar em que áreas da vida dos participantes, eles mais necessitam de informação. Solicitamos que apresentassem exemplos de situações em que necessitaram de informação e como costumam fazer para se informar. A maioria disse precisar de informações relacionadas a saúde e para coisas específicas do cotidiano, como informações sobre locomoção e transportes. Com relação a como eles fazem para se informar, alguns disseram que quando necessitam de informação, perguntam às pessoas da família, outros que assistem televisão, ouvem rádio ou procuram em algum livro.

Na dinâmica realizada, podemos identificar gostos e interesses dos participantes, no intuito de compreender como a BCCF poderia trabalhar para realizar atividades e serviços que atraiam o público idoso para a biblioteca. Nesse momento, foi possível compreender que os principais interesses dos indivíduos do grupo envolvem atividades com seus familiares, de cunho cultural e de leitura, e a participação em atividades do Projeto Criança Feliz, como cursos de capacitação e atividades de grupo.

Os dados coletados nessa atividade em grupo nos possibilitaram perceber os diversos aspectos envolvidos nas necessidades informacionais do grupo estudado. Para analisar essas necessidades, seguimos os pontos estabelecidos no modelo de Savolainen (1995), por meio dos quais identificamos quatro principais categorias de análise, relacionadas a ocupação do tempo no cotidiano, situações problemáticas nas quais os mesmos necessitaram de informação e de que forma solucionaram esses problemas, e Inf. Pauta, Fortaleza, CE, v. 2, número especial, out. 2017 
ainda fatores que podem ter influenciado nesses processos. Logo a seguir, apresentamos as categorias identificadas por meio da pesquisa.

\section{Categoria 1 - Ocupação do tempo e vida diária}

Acerca desse aspecto, identificamos que a maioria dos participantes da pesquisa não possui ocupação profissional ou uma ocupação fixa de tempo referente ao trabalho. Quanto ao cotidiano, compreendemos que os mesmos possuem atividades ligadas principalmente ao ambiente familiar, e que alguns também costumam participar de cursos e grupos de convivência do PROCIF. Muitos assumem também a responsabilidade de cuidar dos netos, enquanto os pais das crianças encontram-se no trabalho, outros dizem que assumem essa função em tempo integral, estes, se autodenominam muitas vezes como pais desses netos.

\section{Categoria 2 - Situações Problemáticas}

No que se refere às situações-problemas apresentadas pelos participantes, os mesmos recordaram situações ligadas à necessidade de informação para locomoção, assim como outras ligadas a questões de saúde, como informações sobre medicamentos, procedimentos médicos, dentre outros. Analisando, podemos inferir que o tipo de informação necessária para o grupo em estudo seriam aquelas voltadas para as necessidades básicas, que se encontram na base da Pirâmide de Barreto (2002), correspondendo, segundo o autor, às informações de tipo utilitária.

\section{Categoria 3 - Comportamento para solução dos problemas}

Para solucionar os problemas, podemos identificar pela fala dos participantes e das situações colocadas pelos mesmos, que a forma com que buscam se informar é principalmente por meio de outras pessoas. A principal fonte de informação dos mesmos é pelo diálogo com familiares, conhecidos ou pessoas ao seu redor. Entretanto, podemos perceber o papel da televisão, rádio e livro sendo citados por eles como formas de buscar e ter acesso à informação. Esse aspecto nos faz lembrar a reflexão de Cavalcante (2014), de que a forma como o fluxo informacional acontece em contextos 
locais é diferente, muitas vezes, dos fluxos de outros âmbitos, como por exemplo, o científico. Em contextos locais, a informação poderá estar imbricada em todo um contexto dialógico, ela acontece também pelas trocas e interações cotidianas entre seus moradores.

\section{Categoria 4 - Fatores situacionais}

Identificamos, ainda, alguns fatores que podem influenciar nas necessidades informacionais e formas de busca da informação dos participantes do estudo. 0 primeiro deles é o contexto social, a realidade em que vivem oferece muitas barreiras informacionais para estes indivíduos. Por outro lado, podem também possibilitar diálogos informacionais que oferecem também possibilidades de acesso à informação. Evidenciamos a autoestima como outro fator, visto que percebemos na fala dos participantes, que eles, muitas vezes, acreditaram que não conseguiriam aprender a utilizar um dispositivo móvel ou a internet, por exemplo, porque, segundo os mesmos, isto não estaria dentro de suas habilidades. Outro aspecto identificado na atividade foi a barreira relacionada com a questão educacional. 0 fator da falta de tempo foi colocado por um dos participantes. A rotina muitas vezes atribulada de cuidar dos netos e da família exige tempo e dedicação, o que faz com que não tenham tempo para atividades como leitura e lazer. 0 poder aquisitivo influencia também nesse processo, por exemplo, um dos participantes do estudo afirma que se tivesse condições financeiras poderia comprar dispositivos tecnológicos, como celular e computador para utilizá-lo quando precisasse de informação.

Na tabela a seguir pode ser vista uma síntese dos resultados obtidos, segundo os pontos do modelo de Savolainen (1995). 
Quadro 1 - Análise das necessidades e fluxos informacionais segundo o modelo ELIS de Savolainen (1995)

\begin{tabular}{|c|c|}
\hline Ocupação do Tempo e Cotidiano & Situações problemáticas \\
\hline Sem ocupação fixa profissional; & Locomoção (localização, ônibus) \\
Participação em cursos e grupos do & Saúde (medicamentos, consultas e \\
PROCIF & $\begin{array}{c}\text { exames médicos) } \\
\text { Outras situações cotidianas }\end{array}$ \\
Atividade relacionadas a família & Fatores Situacionais \\
\hline Comportamento para solução dos & Fator Socioeconômico \\
problemas & Autoestima \\
Busca de informação com outras pessoas, \\
como familiares, amigos, vizinhos etc. \\
Assistir televisão, ouvir rádio, ler livros \\
\end{tabular}

Fonte: dados da pesquisa.

Pelo exposto, podemos compreender que as necessidades informacionais do grupo de idosos estudado partem principalmente do cotidiano dos mesmos. Esses indivíduos precisam, sobretudo, de informação para resolver questões do dia a dia, ou seja, informação do tipo utilitária. Vimos que no cotidiano desses indivíduos existem fatores e barreiras que podem dificultar o acesso à informação. Entretanto, essas barreiras são superadas muitas vezes pelos diálogos possibilitados pela comunidade, família e ações desenvolvidas por projetos sociais como o PROCIF.

Considerando esses aspectos, é necessário que a BCCF busque contemplar esse público da comunidade em seus serviços e produtos oferecidos. 0 caminho para que isto ocorra demanda que a biblioteca esteja atenta a esses processos dialógicos existentes no interior da comunidade. Segundo Cavalcante (2014, p. 263) essas redes simbólicas de troca de informação também constroem e dão novos significados às demandas informacionais, que "para além das especificidades e complexidades desses usuários, no interior das comunidades locais eles são híbridos e plurais porque senhores dos papéis sociais que desempenham no interior de seus grupos."

Em suma, o grupo estudado nos fez perceber que a BCCF se encontra diante de necessidades informacionais bastante diversas, onde algumas delas são muitas vezes simples de resolver; outras, por sua vez, demandam maiores esforços por parte da gestão da biblioteca. 0 processo de inclusão informacional, o qual é colocado como sendo o principal objetivo da biblioteca, para se tornar efetivo precisará contemplar os diversos grupos existentes na comunidade, e é preciso compreender que cada grupo revelará diferentes tipos de necessidades informacionais. 


\section{CONSIDERAÇÕES FINAIS}

A forma como os fluxos informacionais ocorrem nas comunidades revelam, muitas vezes, a criatividade e a pluralidade de maneiras encontradas por seus indivíduos para se informar. A própria existência da biblioteca comunitária já denuncia que os moradores buscam formas alternativas para ter acesso à informação e à leitura. Isto acontece porque os equipamentos públicos, como por exemplo, a biblioteca pública, encontram-se distante tanto na localização, quanto pelas formas como oferecem informação, que são, de modo geral, padronizadas, e que nem sempre correspondem às demandas e necessidades informacionais de certos indivíduos.

Por estas razões, podemos identificar que as atividades e serviços oferecidos pela BCCF envolvem diversas atividades de cunho cultural e informacional. Entretanto, essas atividades são na maioria direcionadas ao público infantil ou jovem, não sendo dada a mesma relevância para o público adulto e idoso. A luta pela igualdade de oportunidade no acesso à informação e à leitura às quais a biblioteca se propõe não pode deixar de lado determinados grupos, ela precisa ser democrática e inclusiva.

Assim, a pesquisa nos possibilitou evidenciar que as necessidades de informação dos participantes da pesquisa estão ligadas principalmente a questões do cotidiano, como informações sobre saúde e locomoção. 0 intuito desta pesquisa foi o de por meio da análise das informações fornecidas pelos participantes da atividade em grupo, identificar a natureza das necessidades informacionais desses indivíduos, para ensejar novas formas de estudo e atuação da biblioteca com relação ao público idoso da comunidade.

O sentido dos estudos de usuários é justamente esse, o de descobrir o que os usuários precisam no contexto informacional para, então, subsidiar o planejamento e execução de ações que permitam a esses indivíduos o acesso à informação de que precisam. Por meio do estudo realizado, acreditamos que ações como oficinas, palestras, cursos e atividades culturais na BCCF podem fazer com que a população de moradores adultos, em especial, os idosos, ampliem a visão que possuem acerca da biblioteca e do seu papel junto à comunidade e, ao mesmo tempo, auxiliar para que a biblioteca possa cumprir sua missão de democratizar o acesso à informação e à leitura. 


\section{AGRADECIMENTOS}

Prestamos aqui nosso agradecimento, a Fundação Cearense de Apoio ao Desenvolvimento Científico e Tecnológico (FUNCAP), pelo financiamento desta pesquisa

\section{REFERÊNCIAS}

ALVES, Mariana de Souza; SALCEDO; Diego Andres; CORREIA, Anna Elizabeth Galvão Coutinho. Um mapeamento da produção científica sobre Bibliotecas Comunitárias na Ciência da Informação brasileira. InCID: R. Ci. Inf. e Doc., Ribeirão Preto, v. 7, n. 2, p. 4066, set. 2016. Disponível em:

<www.revistas.usp.br/incid/article/download/107260/118485>. Acesso em: 15 out. 2016.

BARRETO, Aldo de Albuquerque. A questão da informação. Disponível em: <http://aldoibct.bighost.com.br/quest/quest2.pdf>. Acesso em: 10 out. 2016.

CAVALCANTE, Lidia Eugênia; A Mediação da Informação sob a Perspectiva do Usuário em Comunidades Locais. In: CASARIN, Helen de Castro Silva. Estudos de Usuários da Informação. Brasília: Thesaurus, 2014.

COSTA, Maria de Fátima Oliveira; SILVA, Vanessa Feitosa Sampaio. A Atuação do Profissional da Informação: responsabilidade e compromisso com usuários de terceira idade. Revista EDICIC, v.1, n.2, p.173-184, abr./jun. 2011. Disponível em: <http://www.edicic.org/revista/>. Acesso em: 02 fev. 2017.

CUNHA, M. B.; AMARAL, S. A.; DANTAS E. B. Manual de estudos de usuários da informação. São Paulo: Atlas, 2015.

FIGUEIREDO, Nice Menezes de. Estudos de uso e usuários da informação. Brasília: IBICT, 1994.

GIL, Antônio Carlos. Métodos e técnicas de pesquisa social. 6. ed. São Paulo: Atlas, 2008.

IPECE. Perfil Básico Municipal. Disponível em: <http://www.ceara.gov.br/?secretaria=IPECE\&endereco=http://www.ipece.ce.gov.br/p publicacoe/perfil_basico/index_perfil_basico.htm> Acesso em: 30 out. 2016.

LE COADIC, Yves-François. A ciência da informação. 2. ed. Brasília, DF: Brinquet de Lemos, 2004.

LUCCA, Djuli Machado; VITORINO, Elizete Vieira. O Desenvolvimento da Competência Informacional dos Idosos: um olhar para as necessidades informacionais desses indivíduos. In: ENCONTRO NACIONAL DE PESQUISA EM CIÊNCIA DA INFORMAÇÃO, 16., 2015, João Pessoa, PB. Anais eletrônicos... João Pessoa: UFPB, 2015. Disponível em: < 
http://www.ufpb.br/evento/lti/ocs/index.php/enancib2015/enancib2015/schedConf/ presentations $>$. Acesso em: 10 nov. 2016.

MACHADO, Elisa Campos. Bibliotecas Comunitárias como Prática Social no Brasil. São Paulo, 2008. Originalmente apresentada como tese de doutorado, Universidade de São Paulo. Disponível em: <http://www.teses.usp.br/teses-/disponiveis/27/27151/tde07012009-172507/pt-br.php>. Acesso em: 20 nov. 2016.

MURANI, Denize Bouttelet. Considerações Teóricas e Técnicas da Utilização do Grupo na Investigação Científica. R Enferm UERJ, Rio de Janeiro, v. 16. n. 1, p. 113-8, jan./mar, 2008.

PIRES, Neusa Maria dos Santos. BARREIRA, Maria Isabel de Jesus Sousa. Necessidades informacionais da pessoa idosa: estudo no contexto da Universidade Aberta à Terceira Idade da UNEB. Dissertação de Mestrado em Ciência da Informação. Salvador: UFBA, 2015. Disponível em: < https://repositorio.ufba.br/ri/handle/ri/19199>. Acesso em: 17 nov. 2016.

RICHARDSON, Roberto Jarry. Pesquisa Social: métodos e técnicas. São Paulo: Atlas, 1985.

SAVOLAINEN, Reijo. Everyday life information seeking: approaching information seeing in the context of way of life. Library and Information Science Research, n. 17, p. 25994, 1995.

WHITAKER. Dulce Consuelo Andreatta. O Idoso na Contemporaneidade: a necessidade de se educar a sociedade para as exigências desse "novo" ator social, titular de direitos. Cad. Cedes, Campinas, v. 30, n. 81, p. 179-188, mai./ago. 2010. Disponível em: < http://www.cedes.unicamp.br/>. Acesso em: 05 nov. 2016. 


\section{SOBRE OS AUTORES}

\section{Ana Pricila Caledônio da Silva}

Mestranda em Ciência da Informação na Universidade Federal do Ceará (UFC).

E-mail: priceledonio@gmail.com

\section{Maria de Fátima Oliveira Costa}

Doutora em Ciência da Informação pela Universidade Estadual Paulista (UNESP).

E-mail: fatima12oliveiracosta@gmail.com

\section{Lídia Eugenia Cavalcante}

Doutora em Educação pela Universidade Federal do Ceará (UFC).

E-mail: cavalcantelidiaeugenia@gmail.com

Recebido em: 07/03/2017; Revisado em: 04/04/2017; Aceito em: 09/05/2017.

\section{Como citar este artigo}

SILVA, Ana Pricila Celedonio; COSTA, Maria de Fátima Oliveira; CAVALCANTE, Lidia Eugenia. Necessidades informacionais de idosos em bibliotecas comunitárias: estudo realizado em uma biblioteca no município de Fortaleza, Ceará. Informação em Pauta, Fortaleza, v. 2, número especial, p. 29-46, out. 2017. 